\title{
Blocos solo-cal utilizando resíduo da construção civil
}

\author{
(Soil-lime bricks using building waste)
}

\author{
S.M.R.Patricio, S. S. Figueiredo, I. M. T. Bezerra, G. A. Neves, H.C. Ferreira \\ Unidade Acadêmica de Engenharia de Materiais/UFCG, Av. Aprigio Veloso 882, Bairro Universitário, \\ Campina Grande, PB 58429-140 \\ gelmires@dema.ufcg.edu.br,solapatricio@hotmail.com,suelensfigueiredo@gmail.com, \\ zabelle_marie@yahoo.com.br,heber@dema.ufcg.edu.br
}

\begin{abstract}
Resumo
Novas técnicas vêm sendo desenvolvidas com o objetivo de incentivar o desenvolvimento sustentável e tentar minimizar a degradação ambiental causada pela extração indiscriminada de recursos naturais além da constante geração de resíduos de construção e demolição. Esta pesquisa objetiva avaliar a utilização de resíduos da construção civil, oriundos de demolição, como agente pozolânico na fabricação de blocos solo-cal. As matérias primas convencionais e alternativas (resíduos) foram caracterizados por meio dos seguintes ensaios: massa especifica real, área específica, análise granulométrica por peneiramento e por difração á laser,limites de liquidez e plasticidade, análise química e difração de raios X. Para os ensaios tecnológicos foram confeccionados corpos de prova solo-cal no traço 1:10 em peso, com substituição da cal por resíduos nas seguintes proporções: 0, 10, 20, 25, 30, 40, 50 e $75 \%$. Os corpos de prova foram curados por períodos de 28, 60 e 90 dias, em câmara úmida com 100\% de umidade relativa, em seguida determinada sua resistência à compressão simples e absorção de água. Com os melhores resultados de resistência a compressão simples, foram moldados blocos solo-cal e solo-cal-resíduo. Os resultados obtidos com os blocos solo-cal incorporados com resíduo evidenciaram valores dentro das especificações das normas da ABNT, apontando que existe viabilidade técnica no aproveitamento de resíduos de demolição para uso na fabricação de blocos solo-cal sem função estrutural.
\end{abstract}

Palavras-chave: resíduos, blocos, solo-cal, pozolana.

\begin{abstract}
New techniques have been developed with the aim of encouraging sustainable development and try to minimize the environmental degradation caused by indiscriminate extraction of natural resources and the constant generation of building waste. This research aims to evaluate the use building waste, as pozzolanic agent in the soil-lime bricks manufacture. Raw materials conventional and alternatives (waste) were characterized by tests: true specific mass, specific area, particle size analysis by sieving and laser diffraction, Atterberg limits, chemical analysis and X-ray diffraction. Technological testing specimens were prepared soil-lime on the proportion 1:10 by weight in place of lime for waste in the following proportions: 0, 10, 20, 25, 30, 40, 50 and 75\%. The specimens were cured for periods of 28,60 and 90 days in 100\% relative humidity chamber, then compressive strength and water absorption were evaluated. With the best results in resistance to simple compression molded bricks were soil-lime and lime-soilresidue. The results obtained with the soil-lime bricks incorporated with residue showed values within the specifications of the $A B N T$, indicating that there is technical feasibility in the use of demolition waste for use in the manufacture of soil-lime bricks with no structural function.
\end{abstract}

Keywords: waste, bricks, soil-lime, pozzolan.

\section{INTRODUÇÃO}

A industrialização e o desenvolvimento dos centros urbanos têm provocado um aumento significativo na geração de resíduos, causando graves impactos ambientais devido ao volume acumulado e as deposições inadequadas. Dentre estes, os resíduos da construção civil representam cerca de $60 \%$ de todos os resíduos sólidos urbanos [1,2]. Construir é uma das atividades mais antigas que se tem conhecimento e desde os primórdios da humanidade foi executada de forma artesanal gerando como subproduto grande quantidade de resíduo mineral. Hoje em dia a indústria da construção civil causa impactos desde a extração da matéria-prima, construção e manutenção, até a demolição de empreendimentos.

Pesquisas de novos materiais e métodos construtivos vêm sendo realizados com o intuito de aumentar a eficiência e o desempenho das edificações, buscando adequar a indústria da construção civil aos conceitos de sustentabilidade [3,4].

$\mathrm{O}$ aproveitamento de resíduos para uso como pozolanas têm sido intensificado nos últimos anos, podendo-se destacar os resíduos de construções e demolição. O uso de resíduos com propriedades pozolânicas é extremamente atraente para uso em construção civil pela substituição dos aglomerantes clássicos e pela minimização dos problemas ambientais causados por esses rejeitos quando descartados ao meio ambiente [5-12]. 
As razões que motivam as pesquisas utilizando resíduos como matéria-prima no desenvolvimento de novos materiais de construção, em geral, são [13]: esgotamento das matériasprimas não renováveis, redução do consumo de energia, menores emissões de poluentes, redução de custos, melhoria na saúde e segurança da população. Assim a reciclagem de resíduos como entulho, resíduos industriais, resíduos de mineração, entre outros, contribuem para a preservação ambiental.

Diversos estudos e pesquisas sobre reciclagem vêm sendo realizados com o objetivo de verificar a qualidade e a viabilidade em se empregar resíduos na produção de novos materiais de construção, visando tornar o setor da construção civil mais sustentável e solucionar graves problemas ambientais causados pela deposição em locais inadequados, dentre estas pesquisas destacam-se os seguintes trabalhos: os blocos de solo estabilizado possibilitam incorporar outros materiais na sua fabricação, como por exemplo, agregados produzidos com entulho reciclado e rejeitos industriais (sílica ativa, cinzas volantes, escórias de alto-fornos, finos de serrarias e outros) [14]. Além disso, por não ser necessária a queima do bloco, há uma excessiva redução do consumo de energia e, por conseqüência, de danos ambientais à sua fabricação. A viabilidade técnica da utilização do resíduo de demolição na fabricação de blocos de alvenaria foi estudada [15]. Os resultados mostraram que os valores de resistências à compressão simples foram superiores aos convencionais, sendo o valor máximo de 5,5 $\mathrm{MPa}$. A incorporação de resíduos da construção e demolição (RCD) em blocos de solo-cimento foi estudada [16]. Os resultados obtidos mostraram que a adição do resíduo de concreto ao solo melhorou as propriedades mecânicas dos tijolos solocimento, possibilitando redução de custos e produção de blocos prensados de melhor qualidade, constituindo-se, portanto, numa excelente alternativa para o aproveitamento deste material. Foi estudada a incorporação de resíduo de EVA, oriundo da fabricação de calçados, em blocos de solocimento [17]. Os resultados evidenciaram que à medida que o teor de EVA foi aumentado, a resistência à compressão dos blocos diminuiu sensivelmente. Apesar da diminuição da resistência dos blocos, a incorporação de resíduo de EVA na mistura de solo com $10 \%$ de cimento em massa atenderam aos critérios da norma de alvenaria de vedação sem fim estrutural. Foram estudados os efeitos da adição da casca de arroz nas propriedades físico-mecânicas da mistura de solo-cimento, visando à obtenção de composições de solocimento-casca de arroz com potencialidade para fabricação de materiais alternativos de construção [18]. Os resultados mostraram que as misturas de solo com teor de $12 \%$ de combinações de cimento e casca de arroz são materiais promissores para a fabricação de elementos construtivos, a serem utilizados em construções e instalações rurais. Foi verificado que o comportamento mecânico de blocos confeccionados com $0 \%, 20 \%, 40 \%$ e $60 \%$ de resíduos de concreto e de 6,8 e $10 \%$ de cimentos, levaram a concluírem que os blocos que possuíam resíduos na sua composição mesmo com menos cimento, eram mais resistentes [19].
Considerando-se a necessidade de minimizar o descarte do resíduo da construção civil (entulho) em condições e locais inadequados e aproveitando a potencialidade físicoquímica desse material, pretende-se, neste trabalho de pesquisa, estudar a viabilidade técnica do aproveitamento desses resíduos para uso em blocos solo-cal. Para tanto, foi incorporado ao solo o resíduo da construção oriundo de demolição aditivado com cal, com a finalidade de obter um material de construção alternativo, de boas características físico-mecânicas, que possa ser utilizado na fabricação de blocos solo-cal para uso em construções.

\section{MATERIAIS E MÉTODOS}

Os materiais utilizados neste trabalho foram: resíduo da construção civil, proveniente da demolição do Laboratório de Solos I da UFCG/Campus I, Campina Grande, PB; solo argiloso proveniente de jazida próxima ao Condomínio Atmosfera,na BR-104 saída de Campina Grande para acidade de Lagoa Seca, PB; cal hidratada conhecida comercialmente como "carbomil", proveniente de fábrica em Limoeiro do Norte, CE, e água potável, fornecida pela Companhia de Águas e Esgotos da Paraíba, para o abastecimento urbano. Os resíduos de demolição foram coletados segundo a norma da ABNT [20], sendo efetuada a separação de materiais indesejáveis, beneficiados utilizando-se um britador de mandíbulas e moinho de galga, peneirados em peneira ABNT $200(0,074 \mathrm{~mm})$, e posteriormente armazenados em sacos plásticos. O solo foi coletado segundo a norma da ABNT [20], seco ao ar, destorroado e passado em peneira ABNT $4(4,8 \mathrm{~mm})$. As amostras de solo submetidas aos ensaios de caracterização foram preparadas de acordo com a norma da ABNT [21]. As matérias-primas utilizadas nesta pesquisa foram submetidas aos ensaios de caracterização através da análise granulométrica por peneiramento (ABNT [22]), difração a laser (Cilas 1064), massa específica real (ABNT [23], área específica pelo método do Blaine (ABNT [24]), limites de liquidez e plasticidade (ABNT [25] e ABNT [26]; análise química por espectrometria de raios $X$ (Shimadzu EDX-700) e difração de raios X (Shimadzu XRD-6000). Para os ensaios tecnológicos, foram moldados corpos de prova cilíndricos com dimensões de $5,0 \mathrm{~cm}$ de diâmetro e $10,0 \mathrm{~cm}$ de altura de solo-cal no traço $1: 10$, de acordo com a norma da ABNT [27]. Foi incorporado a este traço o resíduo em substituição a parte do aglomerante (cal) nos percentuais de $0,10,20,25,30,40,50$ e $75 \%$. O fator água/ aglomerante foi 1,98 , determinado pela umidade ótima do ensaio de compactação. Após moldagem, os corpos de prova foram curados por 28,60 e 90 dias, em câmara úmida com $100 \%$ de umidade relativa e temperatura $22 \pm 0,5^{\circ} \mathrm{C}$. Após o processo de cura os corpos de prova foram submetidos aos ensaios de resistência à compressão simples e absorção de água. Para a confecção dos tijolos foram escolhidos os traços dos corpos de prova de referência (solo-cal) e incorporados com resíduo que conduziram os melhores resultados de resistência à compressão simples. Para a moldagem dos tijolos foi utilizada uma prensa manual marca Modelar - 
Sahara, com dimensões $12,5 \mathrm{~cm}$ x $25,0 \mathrm{~cm}$ x $6,25 \mathrm{~cm}$. Após moldagem os blocos solo-cal foram curados por 28,60 e 90 dias nas condições já descritas anteriormente.

A resistência à compressão simples dos corpos de prova cilíndricos foi determinada conforme a metodologia proposta na norma ABNT [27]. Para os blocos prensados a resistência à compressão simples foi determinada de acordo com a norma da ABNT [28], que foi adaptada, visto que esta norma se refere a blocos maciços de solo-cimento. A RCS foi determinada em uma máquina universal Shimadzu AGIS com célula de $100 \mathrm{kN}$; a velocidade do ensaio foi 0,5 $\mathrm{kgf} / \mathrm{s}$. Os resultados de RCS representam a média de cinco corpos de prova.

Para a determinação da absorção de água foi seguida a metodologia recomendada pela norma ABNT [28]. Os resultados de absorção de água representam a média de três corpos de prova.

\section{RESULTADOS E DISCUSSÃO}

A Tabela I apresenta os percentuais dos materiais que compõem o resíduo de demolição utilizado neste trabalho de pesquisa.

Tabela I - Materiais que compõem o resíduo de demolição. [Table I - Demolition waste materials composition.]

\begin{tabular}{cc}
\hline Materiais & Massa $(\%)$ \\
\hline material cerâmico & 32,64 \\
argamassa & 36,34 \\
concreto & 25,38 \\
revestimento & 5,64 \\
\hline
\end{tabular}

Oresíduo é composto em maior quantidade de argamassas $(36,3 \%)$ e materiais cerâmicos $(32,6 \%)$. Este resultado pode estar relacionado à tipologia construtiva mais utilizada no Brasil, que é de alvenaria cerâmica com revestimento argamassado. A Tabela II apresenta os resultados da massa específica real e área específica das matérias-primas utilizadas neste trabalho de pesquisa.

Tabela II - Massa específica real e área específica das matérias primas.

[Table II - True specific mass and specific area of raw materials.]

\begin{tabular}{ccc}
\hline Amostras & $\begin{array}{c}\text { Massa específica real } \\
\left(\mathrm{g} / \mathrm{cm}^{3}\right)\end{array}$ & $\begin{array}{c}\text { Área específica } \\
\left(\mathrm{m}^{2} / \mathrm{g}\right)\end{array}$ \\
\hline solo & 2,60 & 1,67 \\
cal carbomil & 2,26 & 1,40 \\
resíduo & 2,56 & 0,40 \\
\hline
\end{tabular}

Os valores de massa específica real foram $2,60 \mathrm{~g} / \mathrm{cm}^{3}$ para o solo, $2,26 \mathrm{~g} / \mathrm{cm}^{3}$ para cal e $2,56 \mathrm{~g} / \mathrm{cm}^{3}$ para o resíduo, estando este valor de acordo com a norma da ABNT [23], na qual a densidade real dos grãos varia de $2,60 \mathrm{~g} / \mathrm{cm}^{3}$ a
$2,80 \mathrm{~g} / \mathrm{cm}^{3}$. Para área específica observa-se que as amostras apresentaram valores de $1,67 \mathrm{~m}^{2} / \mathrm{g}, 1,40 \mathrm{~m}^{2} / \mathrm{g} 0,40 \mathrm{~m}^{2} / \mathrm{g}$ para o solo, cal carbomil e o resíduo respectivamente, constatando que a maior finura é verificada para o solo em relação aos outros materiais. A superfície específica do resíduo de demolição apresentou valor $0,40 \mathrm{~m}^{2} / \mathrm{g}$, estando este valor de acordo com os resultados dos resíduos estudados [29], que variaram de $0,34 \mathrm{~m}^{2} / \mathrm{g}$ a $0,48 \mathrm{~m}^{2} / \mathrm{g}$. Esta propriedade física influencia diretamente na superfície de contato e poderá permitir um aumento na atividade pozolânica e, conseqüentemente, no comportamento mecânico das amostras. Este comportamento foi observado [29].

A Tabela III apresenta os resultados da distribuição granulométrica por peneiramento e índices físicos do solo.

O solo apresentou teor de silte+argila inferior a $50 \%$, limite de liquidez inferior a $45 \%$ e limite de plasticidade inferior a $18 \%$, estando estes valores dentro da especificação da norma da ABNT [30], para uso em solo cimento. De acordo com os resultados da análise granulométrica e limites de Atterberg, o solo teve sua classificação segundo a AASHTO (American Association of State Highway and Transportation Officials) como A-4: solo siltoso e como SC: areia argilosa e mistura de areia e argila mal graduada, de acordo com a Classificação Unificada dos Solos (The Unified Soil Classification System - USCS).

A Fig. 1 apresenta as curvas de distribuição granulométrica, obtida por difração a laser, do solo, da cal e do resíduo de demolição utilizados neste trabalho.

O solo apresentou massa acumulada da fração argila $(<2 \mu \mathrm{m})$ de $5,55 \%$, a fração silte $(2 \mu \mathrm{m}<\mathrm{X}<60 \mu \mathrm{m}) \mathrm{de}$ $83,77 \%$ e a fração areia $(60 \mu \mathrm{m}<\mathrm{X}<2000 \mu \mathrm{m})$ de $10,68 \%$. Para cal observa-se massa acumulada da fração argila $(<2 \mu \mathrm{m})$ de $24,14 \%$, fração silte $(2 \mu \mathrm{m}<\mathrm{X}<60 \mu \mathrm{m})$ e de $75,66 \%$ e a fração areia $(60 \mu \mathrm{m}<\mathrm{X}<2000 \mu \mathrm{m})$ de $0,2 \%$.

Tabela III - Distribuição granulométrica e índice físico do solo.

[Table III - Particle size distribution and soil physical index.]

\begin{tabular}{|c|c|c|}
\hline & \multirow{2}{*}{ Ensaio } & $\begin{array}{l}\text { Amostra } \\
\text { de Solo }\end{array}$ \\
\hline & & $\begin{array}{c}\text { Resumo da } \\
\text { Granulometria }\end{array}$ \\
\hline \multirow{4}{*}{ 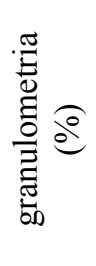 } & pedregulho (acima de 2,0 mm) & 6,43 \\
\hline & areia grossa $(2,0-0,42 \mathrm{~mm})$ & 27,49 \\
\hline & areia fina $(0,42-0,074 \mathrm{~mm})$ & 30,77 \\
\hline & silte+argila & 35,31 \\
\hline \multirow{3}{*}{ 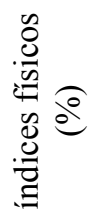 } & LL (limite de liquidez) & 33,0 \\
\hline & LP (limite de plasticidade) & 22,0 \\
\hline & IP (índice deplasticidade) & 11,0 \\
\hline
\end{tabular}




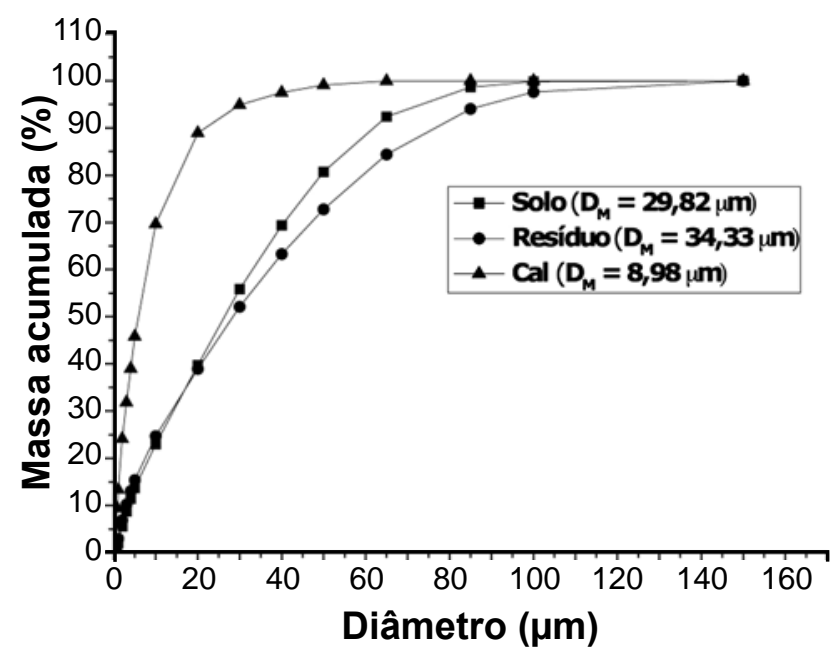

Figura 1: Distribuição de tamanho de partículas do solo, do resíduo e da cal.

[Figure 1: Particles size distribution soil, waste and lime.]

Para o resíduo de demolição, verifica-se massa acumulada da fração argila $(<2 \mu \mathrm{m})$ de $6,84 \%$, fração silte $(2 \mu \mathrm{m}<\mathrm{X}<$ $60 \mu \mathrm{m})$ de $74,03 \%$ e a fração areia $(60 \mu \mathrm{m}<\mathrm{X}<2000 \mu \mathrm{m})$ de $19,13 \%$.

A Tabela IV apresenta a composição química das amostras de solo, cal e resíduo de demolição.

$\mathrm{O}$ solo apresentou elevados teores de sílica $\left(\mathrm{SiO}_{2}\right)$, alumina $\left(\mathrm{Al}_{2} \mathrm{O}_{3}\right)$ e óxido de ferro $\left(\mathrm{Fe}_{2} \mathrm{O}_{3}\right)$, totalizando cerca de $85 \%$ da composição total. A sílica presente no solo é provavelmente proveniente do argilomineral, feldspato e sílica livre. A alumina é oriunda da fração argilosa e da mica e a presença de óxido de ferro é responsável por conferir cor avermelhada ao solo. Para a amostra da cal, observa-se um elevado teor de óxido de cálcio $(\mathrm{CaO})$ de $71 \%$ e baixo teor de óxido de magnésio $(\mathrm{MgO})$ de 1,70\%. Segundo a Norma da ABNT [31], a cal utilizada pode ser classificada como cal calcítica, por apresentar teores de óxido de cálcio superior a $65 \%$ e de óxido de magnésio inferior a 3,0\%. Para o resíduo de demolição (RD), verifica-se que este apresentou elevado teor de sílica $\left(\mathrm{SiO}_{2}\right)$, óxido de alumínio $\left(\mathrm{Al}_{2} \mathrm{O}_{3}\right)$ e óxido de ferro $\left(\mathrm{Fe}_{2} \mathrm{O}_{3}\right)$, totalizando cerca de $74 \%$ da composição total. Esses resultados superam o valor mínimo de $70 \%$ exigido pela ASTM C [32], indicando assim que o resíduo de demolição estudado provavelmente apresenta atividade pozolânica. Além disso, o percentual de $\mathrm{MgO}$ também está abaixo do valor máximo de $5 \%$ sugerido por esta norma.

A Tabela $\mathrm{V}$ apresenta os valores obtidos para as características físicas e químicas do resíduo, e as especificações de varias normas para que apresente atividade pozolânica.

Observa-se que o resíduo apresentou soma dos teores de $\mathrm{SiO}_{2}, \mathrm{Al}_{2} \mathrm{O}_{3}$ e $\mathrm{Fe}_{2} \mathrm{O}_{3}$ superior a $70 \%$ e percentagem de partículas maior do que $45 \mu \mathrm{m}$ inferior $34 \%$, estando esses valores dentro das especificações das normas IS [33], ASTM [32] e ABNT [34] para que material tenha atividade pozolânica.

A Fig. 2 apresenta os difratogramas do solo, da cal e do resíduo utilizados na pesquisa.

O solo apresentou as seguintes fases minaralogicas: caulinita $\left(\mathrm{Al}_{2} \mathrm{Si}_{2} \mathrm{O}_{5}(\mathrm{OH})_{4}\right)$, quartzo $\left(\mathrm{SiO}_{2}\right)$, calcita $\left(\mathrm{CaCO}_{3}\right)$ e menor quantidade de mica $\left(\mathrm{KMg}_{3}\left(\mathrm{Si}_{3} \mathrm{Al}\right) \mathrm{O}_{10}(\mathrm{OH})_{2}\right)$. Para cal, verifica-se as fases de portlandita $\left(\mathrm{Ca}(\mathrm{OH})_{2}\right)$ e calcita

Tabela IV - Composição química do solo, cal e resíduo.

[Table IV - Chemical composition of the soil, lime and waste.]

\begin{tabular}{cccccccccc}
\hline & \multicolumn{1}{c}{ Composição química (\%) } \\
\cline { 2 - 10 } & $\mathrm{SiO}_{2}$ & $\mathrm{Al}_{2} \mathrm{O}_{3}$ & $\mathrm{Fe}_{2} \mathrm{O}_{3}$ & $\mathrm{~K}_{2} 0$ & $\mathrm{Ca} 0$ & $\mathrm{Mg} 0$ & $\mathrm{Ti}_{2}$ & $\begin{array}{c}\text { Outros } \\
\text { Óxidos }\end{array}$ & \multirow{2}{*}{ P.F.* $^{*}$} \\
\hline solo & 45,8 & 33,00 & 5,80 & 1,80 & 1,00 & 0,90 & 0,50 & 0,20 & 11,06 \\
cal & 0,70 & 0,40 & 0,20 & 0,30 & 70,70 & 1,70 & - & 0,10 & 26,00 \\
RD & 48,10 & 19,20 & 6,00 & 2,60 & 11,60 & 2,20 & 0,90 & 1,10 & 8,30 \\
\hline
\end{tabular}

*Perda ao Fogo

Tabela V - Características física e química do resíduo e especificações.

[Table V - Waste physical and chemical characteristics and specifications.]

\begin{tabular}{ccccc}
\hline Determinações & IS [33] & $\begin{array}{c}\text { ASTM } \\
{[32]}\end{array}$ & ABNT[34] & $\begin{array}{c}\text { Resíduo } \\
(\%)\end{array}$ \\
\hline $\mathrm{SiO}_{2}+\mathrm{Al}_{2} \mathrm{O}_{3}+\mathrm{Fe}_{2} \mathrm{O}_{3}$-min & $70 \%$ & $70 \%$ & $70 \%$ & 79,92 \\
$\mathrm{SiO}_{2}-\min$ & $40 \%$ & $\mathrm{NL}$ & $\mathrm{NL}$ & 52,45 \\
Diâmetro médio $(\mu \mathrm{m})$ & $\mathrm{NL}$ & $\mathrm{NL}$ & $\mathrm{NL}$ & 34,33 \\
Partículas $>45 \mu$ m -máx. & $12 \%$ & $34 \%$ & $34 \%$ & 32,00 \\
Perda ao fogo - máx. & $5 \%$ & $10 \%$ & $10 \%$ & 8,3 \\
\hline
\end{tabular}

NL: parâmetro não legislado pela norma de referência 


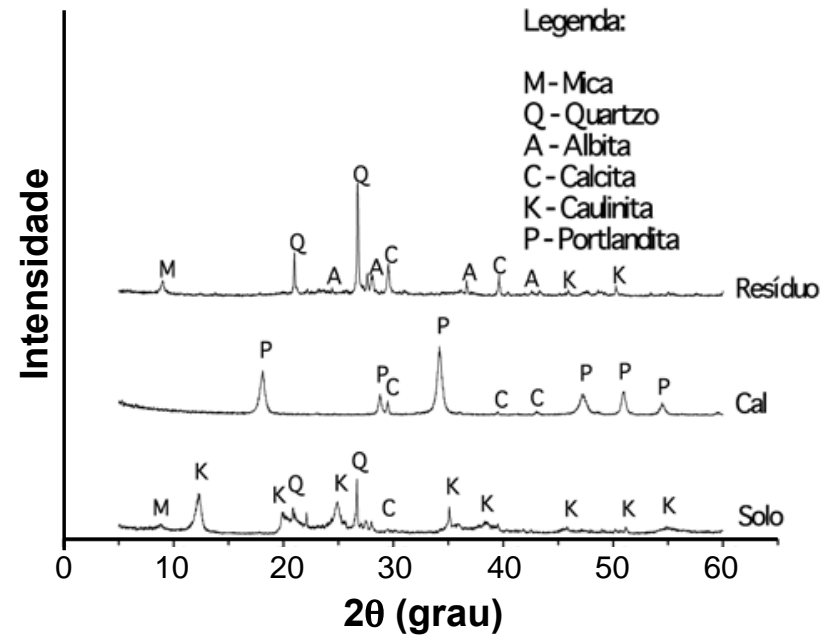

Figura 2: Difração de raios X do solo, da cal e do resíduo.

[Figure 2: Soils, lime and waste X-ray diffraction.]

$\left(\mathrm{CaCO}_{3}\right)$. Para o resíduo, evidencia-se as seguintes fases: albita $\left(\mathrm{Na}\left(\mathrm{Si}_{3} \mathrm{Al}\right) \mathrm{O}_{8}\right)$, caulinita $\left(\mathrm{Al}_{2} \mathrm{Si}_{2} \mathrm{O}_{5}(\mathrm{OH})_{4}\right)$, quartzo $\left(\mathrm{SiO}_{2}\right)$, e menor quantidade de calcita $\left(\mathrm{CaCO}_{3}\right)$ e mica $\left(\mathrm{KMg}_{3}\left(\mathrm{Si}_{3} \mathrm{Al}\right) \mathrm{O}_{10}(\mathrm{OH})_{2}\right)$.

A Fig. 3 apresenta resultados da resistência à compressão simples (RCS) dos corpos de prova solo-cal (referência) e incorporados com resíduo.

A resistência à compressão simples dos corpos de prova incorporados com 10\%, 20\%, 25\%, 30\%, $40 \%$ e $50 \%$ de resíduo de demolição aos 28 dias e com $10 \%, 20 \%$ e $25 \%$ de resíduo para os períodos de cura de 60 dias e 90 dias, conduziram a valores superiores aos de referência, sendo o valor máximo com $25 \%$ de resíduo de 2,24 MPa, 3,99 $\mathrm{MPa}$ e 4,97 MPa aos 28, 60 e 90 dias de cura respectivamente. A resistência à compressão simples dos corpos de prova incorporados com $20 \%$ e $25 \%$ de resíduo, para períodos de cura de 60 e 90 dias foram os que conduziram aos melhores

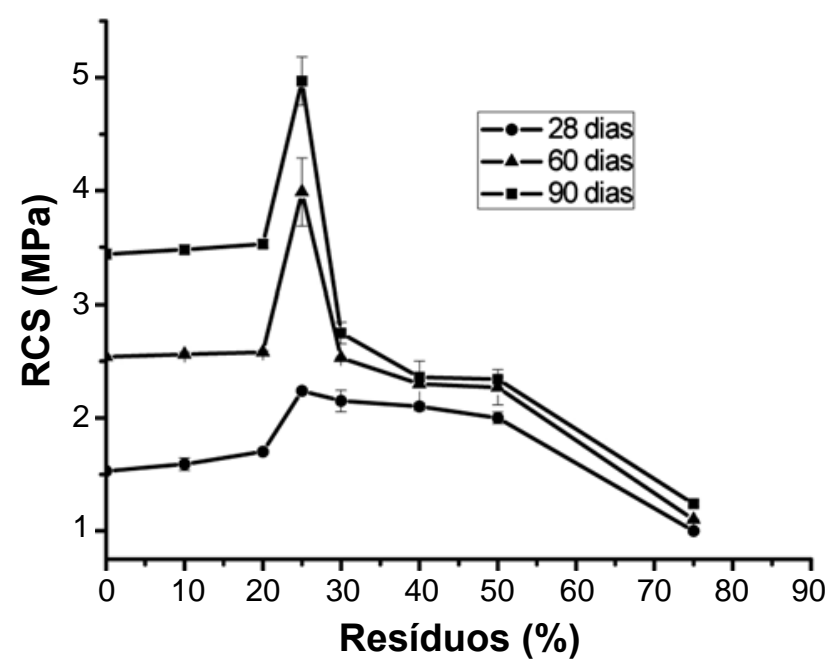

Figura 3: Resistência à compressão simples (RCS) dos corpos de prova solo-cal e solo-cal-resíduo.

[Figure 3: Soil-lime and lime-soil-waste specimens compressive strength (RCS).] resultados. De maneira geral os valores apresentados, identificam que o comportamento mecânico dos corpos de prova foi aumentado com o período de cura. Isto vem confirmar que quanto maior o tempo de cura maior a atividade pozolânica. Comparando os resultados com a norma da ABNT [35], verifica-se que todos os valores para 60 e 90 dias de cura foram superiores as especificações que é de 2,0 MPa, com exceção dos corpos de prova incorporados com $75 \%$ de resíduo em todos os períodos de cura.

A Fig. 4 apresenta os difratogramas de raios $\mathrm{X}$ dos corpos de prova solo-cal com a incorporação de $25 \%$ de resíduo de demolição para os períodos de cura de 28, 60 e 90 dias. Neste trabalho só apresentaremos os difratogramas de raios $\mathrm{X}$ com adição de $25 \%$ de resíduo, por ter sido o de melhor resultado.

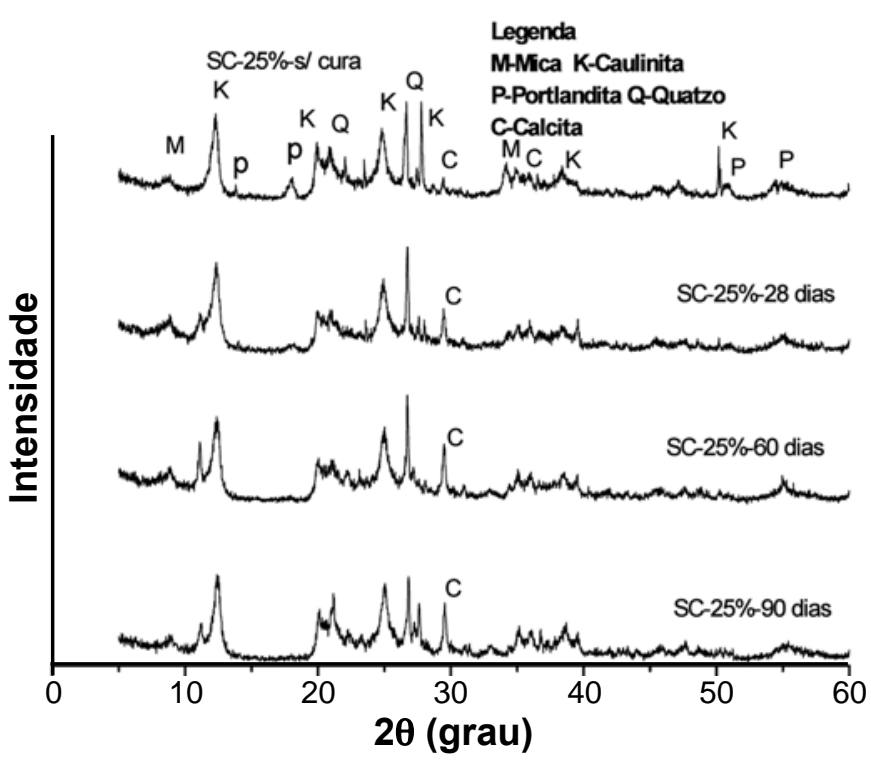

Figura 4: Difratogramas de raios $\mathrm{X}$ dos corpos de prova solo-cal com a incorporação de $25 \%$ de resíduo.

[Figure 4: X-ray diffraction patterns of soils-lime with addition of $25 \%$ of waste specimens.]

Verificam-se as seguintes fases mineralógicas: caulinita $\left(\mathrm{Al}_{2} \mathrm{Si}_{2} \mathrm{O}_{5}(\mathrm{OH})_{4}\right)$, caracterizada pelas distâncias interplanares $7,21 \AA$ e $3,19 \AA$; p portlandita $\left(\mathrm{Ca}(\mathrm{OH})_{2}\right)$, caracterizada pelas distâncias interplanares 2,62 ̊, 5,60 ̊ e 3,23 $\AA$; mica $\left(\mathrm{KMg}_{3}\left(\mathrm{Si}_{3} \mathrm{Al}\right) \mathrm{O}_{10}(\mathrm{OH})_{2}\right)$ caracterizada por $10,04 \AA$; calcita $\left(\mathrm{CaCO}_{3}\right)$ caracterizada por $3,03 \AA$ e $2,13 \AA$ e quartzo $\left(\mathrm{SiO}_{2}\right)$, caracterizado pela distância interplanar 3,34 $\AA$. Observa-se também que com o aumento do período de cura dos corpos de prova, houve um aumento na intensidade dos picos de calcita e uma diminuição da portlandita, evidenciando a reação pozolânica. Estes resultados confirmam os valores de resistências à compressão serem superiores aos 90 dias de cura.

A Fig. 5 apresenta resultados de absorção de água dos corpos de prova sem resíduo de demolição (referência) e incorporados com resíduo.

Para os corpos de prova de solo-cal incorporados com resíduo de demolição os valores de absorção de água se mantiveram abaixo do limite estabelecido pela norma ABNT 


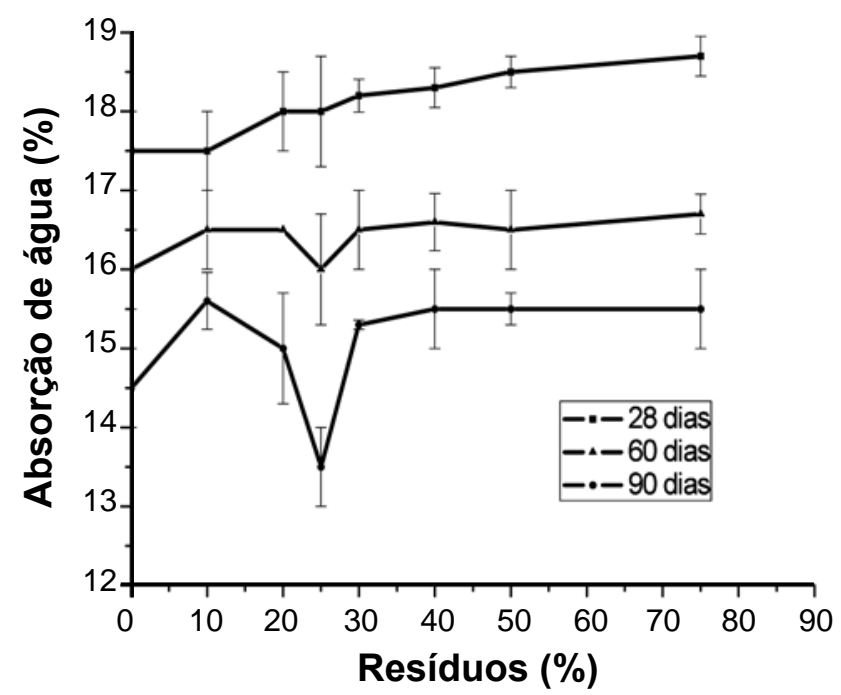

Figura 5: Absorção de água dos corpos de prova solo-cal e solocal-resíduo.

[Figure 5: Soils-lime-soil-lime residue specimens water absorption.]

[35] que é de 20\%. A absorção de água tende a aumentar com a incorporação do resíduo e a diminuir com o tempo de cura.

A Fig. 6 apresenta resultados da resistência à compressão simples dos blocos sem resíduo (referência) e incorporados com resíduo. Os blocos solo-cal incorporados com resíduo foram superiores aos traços de referência (solo-cal), sendo o valor máximo de 2,26 MPa para período de cura de 90 dias. Esta evolução de resistências ao longo do tempo poderá ser atribuída à reação pozolânica entre solo-calresíduo (propriedades cimentantes). Comparando esses resultados com as especificações das normas da ABNT [35], verifica-se que os valores obtidos para período de cura de 90 dias estão dentro das especificações que é de 2,0 MPa.

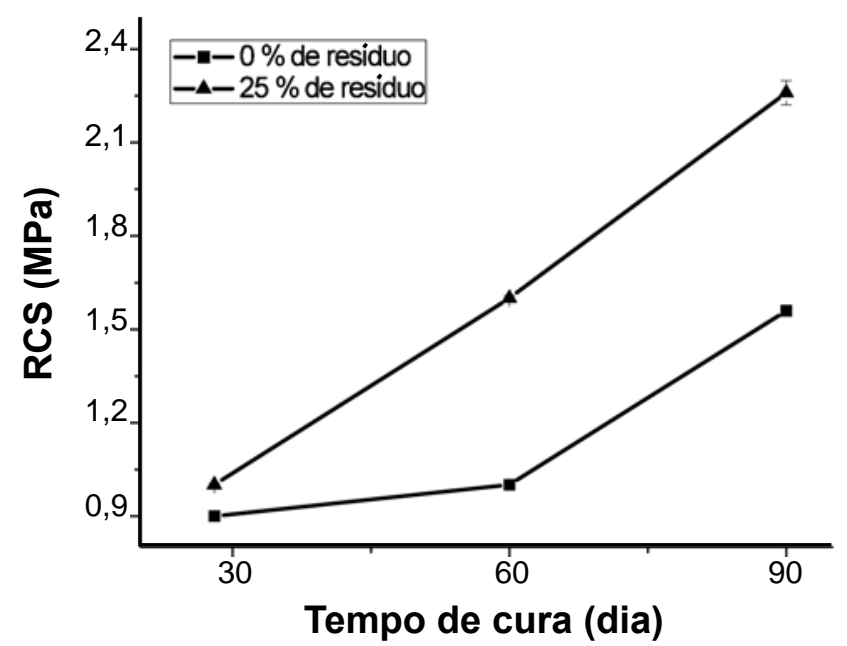

Figura 6: Resistência à compressão simples dos blocos solo-cal e solo-cal-resíduo.

[Figure 6: Soils-lime and soils-lime-waste blocks compressive strength.]
Em relação aos corpos de prova cilíndricos, os valores de RCS foram superiores aos dos blocos solo-cal-resíduo. Este aumento poderá ser justificado pelo fato da geometria dos furos favorecer a concentração de tensões, onde a área perpendicular à força é cerca de $70 \%$ menor que a área líquida do tijolo.

A Fig. 7 apresenta os valores obtidos para a absorção de água dos blocos de referência e incorporados com resíduo.

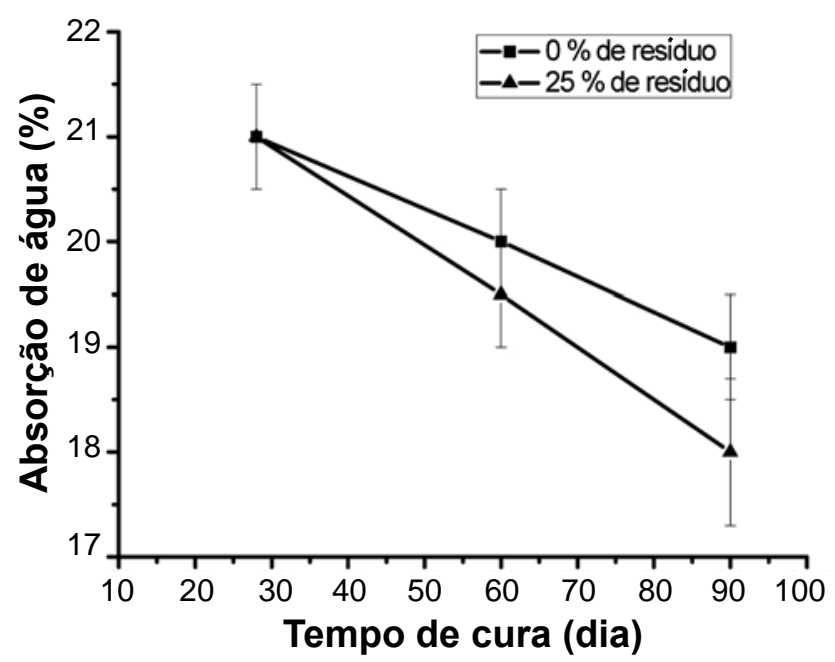

Figura 7: Absorção de água dos blocos solo-cal e solo-cal-resíduo. [Figure 7: Soisl-lime and soils-lime-waste blocks water absorption.]

Os valores de absorção de água dos tijolos diminuíram em relação ao tempo de cura e também com a incorporação de resíduo de demolição, sendo o valor máximo de $21 \%$ para 28 dias de cura. Comparando os resultados com a norma da ABNT [28] verifica-se portanto que os blocos de referência e com $25 \%$ de resíduo de demolição aos 60 e 90 dias de cura estão de acordo com a norma, com exceção dos blocos aos 28 dias de cura.

\section{CONCLUSÃO}

Os resultados obtidos com os tijolos solo-cal incorporados com resíduos evidenciaram valores superiores aos convencionais de acordo com as especificações da ABNT, apontando que existe viabilidade técnica no aproveitamento deste resíduo de demolição para uso na fabricação de tijolos solo-cal sem função estrutural.

\section{REFERÊNCIAS}

[1] G. L. Vieira, D. C. C. Dal Molin, F. B. Lima, Engenharia Civil, UM. 19 (2004) 18-24.

[2] M. B. Leite, D. D. Molin, Sitientibus, Feira de Santana, BA 26 (2002) 111-130.

[3] S. C. Angulo, V. M. John, Rev. Ci. Tecnol. Mater. Const. Civil 1, 1 (2004) 22-32.

[4] J. Farias Filho, G. A. Neves, H. S. Ferreira, J. W. B. do 
Nascimento, R. R. Menezes, L. F. L. Lucena, Land Contam. \& Reclam. 18, 4 (2011) 389-395

[5] K. Wang, H. Hsieh, Cement Concrete Res. 31, 13 (2004) 5.

[6] S. Cara, G. Carcangiu, L. Massidda, P. Meloni, U. Sanna, M. Tamanini, Appl. Clay Sci. 33, 1 (2006) 66-72.

[7] J. V. Nardi, D. Hotza, Mater. Res. 7, 2 (2004) 373-375.

[8] A. Rocha, G. A. Neves, J. B. Q. Carvalho, Int. Conf. Energy, Environment and Disaster (INCEED 2005), Charlotte, NC, EUA (2005) 1-12.

[9] D. F. Oliveira, Contribuição ao estudo da durabilidade de blocos de concreto produzidos com a utilização de entulhos da construção civil, Tese Dr., UFCG, PB (2004) 218p.

[10] G. E. Baronio, L. Binda, Construction Building Mater. 11, 1 (1997) 41-46.

[11] A. M. H. Henao. E. A. A. López, Rev. Ci. Tecnol. Mater. Const. Civil 1, 1 (2004) 33-46.

[12] D. O. Nik, Cemente Concrete Composite 27 (2005) 315-318.

[13] V. M. John, Reciclagem de resíduos na construção civil - contribuição à metodologia de pesquisa e desenvolvimento, Tese Livre Doc., Escola Politécnica, USP, S. Paulo, SP (2000) 180p.

[14] A. P. Carneiro, I. A. S. Brum, J. C. S. Cassa, Reciclagem de entulho para produção de materiais de construção, Projeto entulho bom, Salvador, BA, EDUFBA (2001) 312.

[15] I. Jadovski, Diretrizes técnicas e econômicas para usinas de reciclagem de resíduos de construção e demolição, Trabalho de conclusão (Mestrado Prof.). UFRGS, Porto Alegre, RS (2005) 178p.

[16] J. G. G. Sousa, Contribuição ao estudo da relação entre propriedades e proporcionamento de blocos de concreto Aplicação ao uso de entulho como agregado reciclado, Diss. Mestrado, UNB, DF (2001) 124p.

[17] E. P. Silva, J. W. B. Nascimento, N. P. Barbosa, A. F. Leal, Rev. Eletr. Mater. Proc. 3, 2 (2008) 44-49.

[18] A. P. S. Milani, W. J. Freire, Eng. Agríc Jaboticabal 26, 1 (2008) 1-10.

[19] A. A. S. Segantini, M. I. B. Pereira, AGRIAMBI 12, 2
(2008) 205-212.

[20] ABNT NBR 10007, Amostragem de resíduos, Rio de Janeiro, RJ (2004).

[21] ABNT NBR 6457, Amostras de solo - Preparação para ensaios de compactação e ensaios de caracterização, Rio de Janeiro, RJ (1986).

[22] ABNT NBR 7181, Solo - Análise granulométrica, Rio de Janeiro, RJ (1984).

[23] ABNT NBR 6474, Determinação de Massa Especifica Real, Rio de Janeiro, RJ (1984).

[24] ABNT NBR 76, Cimento Portland-Determinação da Finura pelo Método do Permeabilidade do Ar (método de Blaine), Rio de Janeiro, RJ (1998).

[25] ABNT NBR 6459, Solo - Determinação do limite de liquidez, Rio de Janeiro, RJ (1984).

[26] ABNT NBR 7180, Solo - Determinação do limite de plasticidade, Rio de Janeiro, RJ (1984).

[27] ABNT NBR 12024, Solo-Cimento - Moldagem e cura de corpos-de-prova cilíndricos, Rio de Janeiro, RJ (1992).

[28] ABNT NBR 8492, Tijolo maciço de solo-cimento Determinação da resistência à compressão e da absorção d'água, Rio de Janeiro, RJ (1984).

[29] J. Farias Filhos, Estudo da durabilidade de argamassas alternativas produzidas de resíduos de construção e granito, Tese Dr., UFCG, PB (2007) 118p.

[30] ABNT NBR 10832, Fabricação de tijolo maciço de solo-cimento com a utilização de prensa manual, Rio de Janeiro, RJ (1989).

[31] ABNT NBR 7175, Cal hidratada para argamassas, Rio de Janeiro, RJ (1992).

[32] ASTM, Standard specification for coal fly ash and raw of calcined natural pozzolans for use as mineral admixtures in concrete, C-618 (2006).

[33] Indian Standards Institution (IS), Specification for burnt clay pozzolan, IS 1344, New Delhi, India (1968).

[34] ABNT, NBR 12653, Materiais Pozolânicos - Exigências químicas e físicas, Rio de Janeiro, RJ (2006).

[35] ABNT, NBR 8491, Tijolo maciço de solo-cimento, Rio de Janeiro, RJ (1984).

(Rec. 22/07/2011, Ac. 11/01/2012) 